\title{
LEITURA DE LETRAS DE MÚSICA EM INGLÊS: CO-CONSTRUÇÃO DE EXPRESSÕES METAFÓRICAS
}

\section{Gisele Luz Cardoso* \& Josalba Ramalho Vieira**}

Resumo: Este estudo investiga como alunos co-constroem em grupos sentidos de expressões metafóricas encontradas em letras de música em inglês. A análise deste processo metafórico foi estudada através de protocolos verbais em grupos. Os resultados evidenciam a dependência do aluno em relação ao professor/pesquisador e à língua materna, ao tentar entender os ítens lexicais nào familiares encontrados nas expressões metafóricas.

Palauras-chave: Metáforas; Cognição; Letras de música; Protocolos verbais em grupos

$* * *$

\section{INTRODUÇÃO}

A metáfora, figura de linguagem antes ligada somente à literatura e, portanto, possuindo apenas um papel retórico', vem sendo estudada e analisada, nos últimos vinte anos, como parte do discurso no dia-a-dia como nos mostram os trabalhos de Lakoff \& Johnson (1980), Cameron \& Low (1999) e Gibbs (1999), o que tem favorecido a produção de uma abordagem mais cognitiva do seu significado. Essa figura de linguagem nos ajuda a compreender conceitos, às vezes, difíceis de expressar numa linguagem mais literal. O processo de co-construção de significado de expressões metafóricas novas, mais particularmente, tem sido pouco explorado. $O$ foco do presente estudo está direcionado especificamente ao processo de co-construçào de significado de expressòes metafóricas em letras de música em língua estrangeira, no presente caso, a língua inglesa, em uma turma de Ensino Médio de uma escola pública de Florianópolis/SC.

Aluna do curso de pós-graduação em Inglés (mestrado) da Universidade Federal de Santa Catarma. PhD cm Lingǘstica pela Universidade Fstadual de Campinas. Atual professora do curso de pósgraduação cm Inglès da UHSSC

Observa-se que, na visào aristoteliana, a metáfora era considerada um desvio da linguagem, tendo portando, um papel apenas retórico. Somente no final da década de setenta, vieram à lu\% publicaçóes (...) sobre a metáfora que cridenciaram o que tem sido chamado de virada cognitiva, como nos lembram Vicira, 1999, e Steen, 1994. 


\section{PROBLEMA}

Há uma tendência nas escolas brasileiras de se evitar usar textos literários, visto que eles aparecem em pouca quantidade nos livros didáticos, como mostra um estudo feito por Gottschalk (2003). Esses livros, muitas vezes de má qualidade, são usados por um grande número de professores de língua materna ou estrangeira como um "porto seguro". "Os livros-texto se tornam insubstituíveis, as respostas prontas se tornam o único lugar seguro para professores no perigoso oceano dos textos literários" (CAVALCANTI \& ZANOTTO, 1994 apud VIEIRA, 1999a, p. 76). Uma das razòes para o pouco uso desse tipo de texto é, possivelmente, o grande número de metáforas presentes neles. Zozzoli, Albuquerque e Santos (1999, p. 99) argumentam que "[...] a grande ocorrência de metáforas em textos representa uma das grandes dificuldades no processo interpretativo". Esse pensamento também está de acordo com Zanotto (1990, p. 118), que diz que a metáfora "constitui um verdadeiro exercício do pensamento analógico e criativo", o que exige "habilidade e conhecimento do professor para serem trabalhadas de forma adequada".

Com relaçào a textos literários em uma segunda língua, a situaçào é ainda pior. Além do problema da interpretação, há outros problemas relacionados ao domínio lingüístico dessa língua. Optou-se neste trabalho por usar letras de música, um gênero da literatura que faz parte do nosso acervo cultural cotidiano. De acordo com McRae (1991), letras de música sào exemplos de textos representacionais (TRPs) porque elas, além de envolverem e estimularem o leitor, também provocam aprendizagem afetiva. Além disso, elas requisitam imaginação e emoção, levando o leitor a experimentar sensaçòes como prazer e dor. TRPs são diferentes de textos informativos tais como artigos de revistas e jornais, que sào chamados de textos referenciais (TRFs) por aquele autor. Este é um dos motivos pelos quais foi escolhido esse tipo de texto. Outro motivo é pelo fato de que os aprendizes em geral gostam de cantar músicas nas aulas de língua estrangeira, apesar de os livros didáticos não trazerem com freqüência exemplos de TRPs, como comprova o estudo feito por Gottschalk (2003), que examinou 830 textos de livros didáticos publicados no Brasil. Dentre eles, $84.5 \%$ foram considerados TRFs e somente $15.4 \%$, TRPs. Sendo que apenas 26 textos dos 830 examinados, eram letras de música.

\section{CONTEXTO}

Em um estudo feito por Barreira (2001), foi constatado que quando leitores "pobres", ou seja, com pouca proficiência na língua inglesa, deparam-se com linguagem metafórica em textos, esse tipo de linguagem dificulta a 
compreensão dos mesmos. Quando há uma má combinação entre o conhecimento prévio do aluno/leitor e a informação contida no texto em inglês, o aprendiz não percebe a incongruência presente na linguagem metafórica (BARREIRA, 2001 Apud BARREIRA, 2003). Assim sendo, a compreensão de textos é dificultada pela existência de linguagem metafórica em letras de música também. Os alunos falham em descobrir o significado intencionado pelo escritor, possivelmente, devido à falta de conhecimento lingǘstico e da cultura dos povos que têm o inglês como língua materna. Como afirma Barreira (2003, p. 4), "os leitores fazem interpretaçòes através de inferências baseadas em seus conhecimentos de mundo e baseadas no próprio texto, não necessariamente compreendendo o que o escritor intencionara".

\section{REVISÃO DA LITERATURA}

Junto com as letras de música estão as expressões metafóricas, que sào seu elemento fundamental. Mas o que são metáforas? Para Lakoff e Johnson (1980, p. 5), "a essência da metáfora é entender uma coisa em termos de outra". Já para Blasko e Briihl (1997, p. 261), "uma importante função da metáfora é a de expressar idéias que são difíceis ou impossiveis de expressar literalmente". Gibbs (1999, p. 34) acrescenta que "[...] a metáfora nào é somente vista em poesia e grandes escritos, mas se infiltra em muitos aspectos do linguajar cotidiano". Expressòes metafóricas estão por toda parte²: em artigos de revistas, anúncios, textos literários e não literários, e, naturalmente, em letras de música. Cameron (2003, p. 2) sugere que:

[...] a metáfora nào é somente um ornamento superficial da linguagem, mas um fenômeno dos processos do pensamento humano; então a metáfora na linguagem do mundo real torna-se um importante foco investigativo. Entender como a metáfora é usada pode nos ajudar a entender melhor como as pessoas pensam, como elas entendem o mundo e umas as outras e como elas se comunicam.

2 Veja, por exemplo, casos em que usamos metáforas sem perceber, quando usamos provérbios como, por excmplo, "igua mole cm pedra dura tanto bate atc que fura", "filho de peixe peixinho é", ou na língua inglesa mesmo, onde há casos de metáforas (como no português) chamadas de "metáforas congeladas" porque o leitor/ouvinte não precisa parar para pensar no significado delas visto que clas sào tão usadas no nosso cotidiano, que o significado delas, fí está arraigado na nossa memória: "Ilc kicked the bucket", "I have butterflies in my stomach" ou o clássico exemplo: "Juliet is the sun" 
Dentre as metáforas possiveis com as quais os leitores se deparam, há aquelas que são familiares a eles e aquelas que sào capazes de deixá-los confusos. Então, familiaridade afeta a maneira com que os leitores processam as metáforas. Blasko \& Briihl (1997, p. 275) têm notado que:

A medida que a familiaridade da metáfora aumenta, a dificuldade na compreensão diminui. É possivel que, uma vez que a metáfora vai se tornando mais familiar, o processamento se acelera, enquanto que a experiência prévia estreita possíveis nuances de interpretação […]. Metáforas mais novas e menos familiares podem requisitar mais tempo para a melhor interpretação [...].

Mas por que metáfora? Essa figura de linguagem e pensamento foi escolhida ao invés de outra figura de linguagem para essa pesquisa porque ela é, como sugere Zanotto (1990, p. 244), uma

figura da imaginação, por se constituir numa base puramente subjetiva. [...] a metáfora desencadeia um processo de associações imagéticas ou verbais, por analogia, que constitui um verdadeiro exercício do pensamento analógico e criativo.

As analogias a serem feitas podem ser incomuns, inesperadas ou inusitadas. Ainda de acordo com Zanotto, desta vez a partir de um estudo feito em 1995, foi sugerido que uma das maneiras de explorar os aspectos cognitivos da metáfora é tentar descobrir os processos mentais envolvidos na compreensão de novas metáforas. O objetivo do estudo de Zanotto (1995) era investigar o processo de compreensào de metáforas novas porque, como ela sugere, quando o leitor tenta entender uma metáfora nova, ele está raciocinando metaforicamente. E se conhecermos melhor como se processa o raciocínio metafórico, será possível trabalhar com ele no ensino de forma consciente e sistemática (e não acidental ou ocasional).

\section{PERGUNTA DA PESQUISA}

Ao longo desse estudo, foi investigado o processo cognitivo de leitura metafórica de alunos adolescentes em sala de aula de língua inglesa em letras de música. A pergunta da pesquisa que norteia este trabalho é: Como os alunos co-ionstroem os significados dos enunciados metafóricos na leitura de letras de musica? 


\section{METODOLOGIA}

\subsection{CONTEXTO E PARTICIPANTES}

Os participantes do presente estudo sào 18 alunos do $1^{\circ}$ ano do Ensino Médio de uma escola pública de Florianópolis/SC. Suas idades variam de 14 a 16 anos. Esse grupo foi escolhido porque é considerado um grupo avançado de inglês por esta escola. Supòe-se que alunos com um nível mais avançado de inglês conseguem negociar significados de vocabulário novo mais facilmente. Os referidos participantes foram dispostos em quatro grupos de quatro a cinco membros em cada um. A autora principal deste artigo (doravante chamada apenas pesquisadora), durante o período da pesquisa, ministrou as aulas, também gravou e filmou os grupos trabalhando simultaneamente. Duas assistentes ajudaram durante as aulas e a professora da classe estava presente o tempo todo para ajudar, se necessário. Os alunos não sabiam os motivos reais da investigação. Foi falado para eles apenas que queríamos saber como eles faziam sentido de certas letras de música em grupos.

\subsection{COLETA E ANÁLISE DOS DADOS}

Duas câmeras de vídeo e quatro gravadores foram usados para coletar os protocolos verbais dos alunos, enquanto eles realizavam as tarefas solicitadas. Havia um gravador em cada grupo de alunos. Os dados consistem em transcriçòes dos protocolos verbais em grupos e das tarefas orais e escritas, além de conversas com os alunos, considerando seus pontos de vista e suas dificuldades de interpretação. Portanto, os dados foram analisados qualitativamente, usando-se procedimentos etnográficos. A triangulação dos dados foi feita posteriormente já que, segundo Diesing (DIESING, 1971 apud WATSON-GEGEO, 1988, p. 584), é uma importante estratégia para se chegar a resultados válidos e confiáveis em trabalho etnográfico.

\subsection{MATERIAL UTILIZADO}

Cinco letras de música foram utilizadas, tendo como tema o AMOR, visto ser grande a quantidade de músicas sobre este assunto e a quantidade de metáforas nelas encontradas. Além disso, as músicas escolhidas estào de acordo com o gosto dos participantes. Para os propósitos do presente estudo, abordaremos apenas os protocolos verbais gerados em uma aula, na qual a letra de música escolhida tinha como titulo "Diamonds on the inside".

A letra completa desta música pode ser encontrada no Apéndice 1. 


\section{ANÁLISE DOS DADOS}

\subsection{A ANÁlISE DOS EPISÓDIOS}

A análise dos dados focaliza momentos particulares relacionados à compreensão de expressões metafóricas encontradas em letras de música. Devido aos limites de espaço, esta pesquisadora focará a análise de uma letra de música especificamente chamada "Diamonds on the inside". A análise aqui estará concentrada em partes dos protocolos verbais relacionados à compreensão da seguinte expressão metafórica: (She made herself a bed of nails/And she's planning on putting it to use de "Diamonds on the inside")."

Ao ler "She made herself a bed", nào há sinal de incongruência (como pode ser visto no Episódio 1). A incongruência aparece quando a aluna $\mathrm{R}$ se depara com a palavra "nails", cujo significado "unhas" (turno 02) em português é conhecido. No entanto, quando descobre que significa "pregos" (turno 09), ela fica confusa e se dá conta de que deve fazer uma interpretaçào figurativa. Entào, "nail" é o foco da metáfora, conhecido também como seu veículo, segundo Cameron (CAMERON, 2003, p. 9). A identificação de um possível foco metafórico, na fala ou no texto, é o primeiro passo para identificar a presença da metáfora (STEEN, 1999 apud CAMERON, 2003, p. 11). Finalmente, a mesma aluna conclui que os versos "She made herself a bed of nails/And she'splanning on putting it to use" podem significar que ela (a personagem no texto da música) colocou "desafios para ela" (turno 10). É interessante salientar que alguns aprendizes (como mostrado nos dados a seguir - turnos 06 e 09) acham necessário traduzir a expressão metafórica antes de alcançarem a interpretação figurativa, ou seja, no contexto desta pesquisa, os aprendizes apelaram para sua língua materna primeiro, para entender as expressòes metafóricas. Além do fato de os aprendizes apelarem para a língua materna, eles também dependem do auxílio da professora como sendo a fonte das respostas para suas dúvidas, como visto no turno 06. Vieira (1999c, p. 54) já havia salientado que existe um desejo arraigado dos alunos de saber as respostas do especialista.

\footnotetext{
() título desta letra pode ser traduzido literalmente como "Diamantes por dentro" (tradução das
autoras).

Oreferido verse pode ser traduzdo literalmente come: "Ela fe\% para cla mesma uma cama de preges "cla cití planejando coloci-la cm uso" (traduçäo das autoras).
} 
Episódio 1 (grupo 2):"

01. R: What is nails?

02. N: Unhas.

03. M: Metal.

04. N: Nail é unha!

05. H: Um pedaço fino de metal ((Ele está lendo a explicaçào para "nails" no glossário)).

06. N: Professora, nail não é unba?

07. Prof: Too.

08. N: Mas, então, o que é esse metal aí?

09. H: No contexto, prego. Ela fe z uma cama de pregos. Ela fez ela mesmo.

10. N: Ela colocou desafios pra ela, né?

11. H: É. Meio que ela colocou desafios pra ela.

O mesmo acontece com outro grupo. Ao ler "She made herself a bed", nào há sinal de problema de entendimento. No entanto, quando a aluna se depara com "nails", há um problema porque ela nào sabe seu significado em português:

\section{Episódio 2 (grupo 3)}

S: "She made herself a bed of nails. Eu nào sei o que é 'nails'. Oh, prof. $O$ que que é "nails'?"

Interpretar o sentido figurado no contexto se torna um problema nào porque a aluna nào consegue entendê-lo, mas porque tem problemas com um item lexical. Conseqüentemente, a aluna tem de traduzir, ou saber o significado de "nails" antes de fazer sentido de sua linguagem figurativa. Em suma, um sentido apropriado é limitado devido a limites lingüísticos e/ou lexicais. No próximo exemplo, outro aluno está ciente de que pode haver um sentido figurativo para "nails" naquele contexto:

Convençōes das transcriçooss utilizadas no presente trabalho: (...). parte irrelevante do discurso que foi omitida; // a frase é transpassada pela transcrita abaiso dela; (()): comentários da pesquisadora; Prof.: a professora da classe; N. II, ctc.: iniciais dos nomes dos alunos; Perq.: a pesquisadora. As partes cm itálico mostram as passagens nas quais os aprendizes estão tentando entender o sentndo literal das expressōes metafóricas, e as partes sublinhadas mostram as passagens em que os estudantes estar tentando adivinhar o sentido figurado. 
Episódio 2 (grupo 3)

S: "Professora, aqui tem outro significado ou é pra pôr literalmente?".

No entanto, o grupo falha, ao fazer sentido dessa expressào, embora a explicação da palavra "nails" estivesse explícita no glossário entregue junto com a letra da música. A falta de conhecimento de que "bed of nails" significa "uma cama de pregos" limitou sua interpretação figurativa da letra. Novamente, houve um problema relacionado ao vocabulário, o que dificultou a interpretação metafórica. Nem a assistência dada por esta pesquisadora, nem a explicação contida no glossário foram suficientes para o grupo fazer sentido da referida expressào. O que se sucede é um jogo interpretativo de adivinhaçōes (GEORGES e DUNDES, 1963 apud ZANOTTO, 1995, p. 250), como se observa no Episódio 2, "o que aliás é um jogo essencialmente metafórico". Esse jogo de adivinhaçòes acontece a partir das pistas textuais deixadas pelo autor do texto, o que possibilita inúmeras inferências por parte dos leitores/ aprendizes. Depois de algumas tentativas de elucidaçào do sentido metafórico, a única conclusão que um dos alunos alcançou foi a de que a pessoa à qual o autor está se referindo é louca ("crazy", na linha 39).

Observa-se que, até chegar a um significado no turno 39, houve uma interação entre os membros do grupo e a pesquisadora, com a intençào de se construir em conjunto, num trabalho colaborativo grupal, uma interpretação. Esse processo é denominado co-construçào de sentido porque o sentido não é construído individualmente, mas sim com ajuda de outros participantes da interação, ou seja, é um trabalho colaborativo. O diálogo que ocorre da interação entre uma pessoa mais experiente e uma menos experiente é chamado de diálogo assimétrico. 'Nos diálogos assimétricos, um dos participantes arroga a si o direito de iniciar, orientar, dirigir e concluir a interaçào e exercer pressào sobre o(s) outro(s) participante(s) (MARCUSCHI, 1986 apud VIEIRA, 1999 b, p. 83). No Episódio 2, observa-se que a professora/pesquisadora tem o papel de participante mais experiente e, então, ajuda os alunos na resoluçào de problemas, neste caso, problemas lexicais. Desse modo, ela leva os participantes a entenderem os significados literais na língua materna, favorecendo a co-construçào de um sentido metafórico.

Episódio 2 (grupo 3):

12. M: A "b" também nào significa nada. Olha só: Ela fe đ para ela mesmo tipo uma cama de unha, de unhas e ela tava planejando em usar.

13. Pesq: Take a look at the context again. What's the meaning of nails? 
14. P: I don't know.

15. M: Unbas?

16. Pesq: No.

17. M: No?

18. P: I never see this.

19. Pesq: No.

20. M: Tá, como que é unha em inglês?

21. Pesq: Nail.

22. M: Ta, mas então é o mesmo jeito que se escreve.

23. Pesq: Yes.

24. M: Ok, cama de metal.[...]

25. Pesq: So, what's the meaning of nails?

26. L: Uma peça de metal.

27. Pesq: A piece of metal, but what metal exactly?

28. M: ((Ela está lendo a explicação para "nail" no glossário)).

29. Pesq: A thin piece of metal having a pointed end // that is forced...

30. $\mathrm{M}$ :

//Que é para juntar dois pedaços?

31. Pesq: ((Eu continuo minha leitura do glossário) ... that is forced into wood or another substance by hitting the other end with a hammer. 32. C: Martelo?

33. Pesq: Hammer is this. Hammer. You use the //hammer to... 34. M:

/ lé aquele negócio.

35. P: Prego.

36. Pesq: Yes.

37. M: Ela fez uma cama de pregos?

38. Pesq: Yes.

39. M: Ai, que legal. Ela era louca.

40. Pesq: So you think she was crazy because she made a bed of nails?

41. M: Yes.

Apesar de estar clara a dificuldade dos aprendizes em compreenderem a letra da música, o sentido exato dos referidos versos continua um mistério. Conseqüentemente, o leitor tem a possibilidade de co-construir qualquer sentido plausível, desde que saiba se justificar (VIEIRA, 1999c). E esta foi a possibilidade dada pela pesquisadora, durante a leitura e construçào de sentido em grupo na coleta de dados. 


\section{CONSIDERAÇÕES FINAIS}

A atividade descrita neste artigo evidencia alguns passos importantes no processo de compreensão da metáfora: 1) a dependência do aluno em relação ao professor/pesquisador, ao tentar entender o vocabulário nào familiar e seu sentido literal, tanto na sua língua màe, quanto na língua estrangeira inglês; 2) a necessidade de os alunos se apoiarem na sua língua materna, a fim de tentar fazer sentido das expressòes, e 3) o jogo de adivinhações representado por momentos quando os aprendizes adivinham sentidos diferentes e possiveis para as expressões metafóricas (ZANOTTO, 1995). Concluindo, pode ser observado que esta atividade, desempenhada através de trabalho em grupo, permitiu aos alunos pensar e trabalhar juntos em um trabalho colaborativo (VIEIRA, 1999b/c). Isto levou-os a uma leitura mais rica e mais criativa, representada pela suma das leituras individuais. Adicionalmente, essa atividade de leitura favoreceu o conhecimento do aluno do processo de leitura e, mais particularmente, do processo de se fazer sentido de expressões metafóricas, e, adicionalmente, esse resultado corrobora os resultados de Zanotto (1995).

Em termos de futuras pesquisas, o que é certo é que mais investigaçōes precisam ser feitas, a fim de se trazer mais luz aos efeitos do trabalho colaborativo em salas de aula de língua estrangeira, com a finalidade de se coconstruirr significados metafóricos em letras de música.

\section{REFERENCIAS}

BARREIRA, V. S. FL Reading Strategies for Metaphor and Word Game Interpretation in a Non-Specialized Magazine: a Case Study. Dissertação (Mestrado em Inglês e Literatura correspondente), Universidade Federal de Santa Catarina, 2003.

BARREIRA, V. S. Reading Comprebension in Reading in EFL: Exploring Puns in Titles of Texts from a Non-specialized Magazine. Monografia não publicada. Universidade da Região de Joinville, 2001.

BLASKO, D. G., e BRIIHL D. S. Reading and Recall of Metaphorical Sentences: Effects of Familiarity and Context. In: Metaphor and Symbol, 12 (4). Lawrence Erlbaum Associates, Inc., 1997, p.261-285.

CAMERON. L., e LOW, G. Researching and Apphing Metaphor. Cambridge: C.U.P., 1999. Metaphor in Educational Discourse. London and New York: Continuum, 2003.

GIBBS, R. Researching Metaphor. In CAMERON, L. e LOW, C. Researching and Applying Metaphor. New York: Cambridge University Press, 1999. 
GOTTSCHALK, M. The Role of Literature in Braqilian High School Contexts. Dissertação (Mestrado em Inglês e Literatura correspondente), Universidade Federal de Santa Catarina, 2003.

GLUCKBERG, S. e KEYS.AR, B. How Metaphors Work. In A. ORTONY (Ed.). Metaphor and Thought. Cambridge: Cambridge University Press, 1979/1993.

L.tKOFF, G. \& JOHNSON, M. Metaphors We Live by. Chicago: University of Chicago Press, 1980.

MCRAE, J. Literature with a Small “"”. London: Macmillan Publishers, 1991.

STEEN, G. Understanding Metaphor in Literature. London and New York: Longman, 1994.

VIEIRA, J. R. Language and Literature: some Dialogic Trodden Ways. In BR IND ÃO, I . F. O. (Ed.). Ilha do Desterro, Florianópolis: v. 37, p. 73-91, 1999a.

Metáforas e conflitos: a leitura de poesia e a discussão em grupo na sala-de-aula de Inglês como literatura estrangeira. 1999b. Tese (Doutorado em lingüística aplicada na área de ensino-aprendizagem de segunda língua e língua estrangeira), Departamento de lingüística aplicada do instituto de estudos da linguagem, UNICAMP, Campinas.

Co-construção e conflito: leitura de poesia na sala de aula de Inglês como literatura estrangeira. Trabalhos em Lingüistica Aplicada. v. 33, p. 1-87, Jan./jun. 1999c.

WATSON-GEGEO, K. Ethnography in ESL: Defining the Essentials. TESOL Quarterly, 22 (4), 575-592, 1988.

ZANOTTO (de Paschoal), M. S. Em busca da elucidação do processo de compreensão da metáfora. Em Pontes, E. (org.) A Metáfora. Campinas: Editora da Unicamp,1990.

, Metáfora, cognição e ensino de leitura. In D.E.L.T.A., São Paulo, v.11, n. 2, p. 241-254, 1995.

ZOZZOLI, R. M. D., ALBUQUERQUE, M. R. O., SANTOS, L. F. The Search for Autonomy: a Challenge for the Student Reader. In: BRANDÃO, I. F. O. (Ed.) Ilha do Desterro, Florianópolis, v. 37, p.73-91, Jul./Dez. 1999. 


\section{APÊNDICE 1: LETRA DA MÚSICA ESCOLHIDA PARA O PRESENTE ARTIGO}

Título: Diamonds On The Inside

Autor: Ben Harper

Álbum: Diamonds on the inside

Gravadora: Virgin Records

I knew a girl

Her name was truth

She was a horrible liar

She couldn't spend one day alone

But she couldn't be satisfied

When you have everything

You have everything to lose

She made berself $a$ bed of nails

And she's planning on putting it to use*

But she had diamonds on the inside

She had diamonds on the inside

She had diamonds on the inside

Diamonds

A candle throws its light into the darkness

In a nasty world so shines a good deed

Make sure the fortune that you seek

Is the fortune that you need

Tell me why the first to ask

Is the last to give every time

What you say and do not mean

Follows you close behind

She had diamonds on the inside

She had diamonds on the inside

She wore diamonds on the inside

Diamonds

Diamonds

Like the soldier long standing under fire

Any change comes as a relief

Let the giver's name remain unspoken

She is just a generous thief

She had diamonds on the inside 
She had diamonds on the inside

She wore diamonds on the inside

She wore diamonds

$\mathrm{Oh}$ - diamonds

She had diamonds

She wore diamonds

Diamonds ${ }^{7}$

Glossário:

Relief (happiness): a feeling of happiness that something unpleasant has not happened or has ended.

Nail (metal): a thin piece of metal having a pointed end that is forced into wood or another substance by hitting the other end with a hammer, and is used esp. to join two pieces or to hold something in place.

Truth (fact): the actual fact or facts about a matter; the quality of being true. Wore: past simple of wear

Thief: a person who steals 